Research Article

\title{
An AHP-DEA Approach of the Bike-Sharing Spots Selection Problem in the Free-Floating Bike-Sharing System
}

\author{
Minjiao Cheng and Wenchao Wei (iD \\ School of Economics and Management, Beijing Jiaotong University, Beijing, China \\ Correspondence should be addressed to Wenchao Wei; weiwenchao@bjtu.edu.cn
}

Received 25 June 2020; Revised 23 August 2020; Accepted 3 September 2020; Published 18 September 2020

Academic Editor: Chi-Hua Chen

Copyright (C) 2020 Minjiao Cheng and Wenchao Wei. This is an open access article distributed under the Creative Commons Attribution License, which permits unrestricted use, distribution, and reproduction in any medium, provided the original work is properly cited.

\begin{abstract}
The Free-Floating Bike-Sharing system (FFBSS) connects users to public transit networks and is an important component of the "last-mile" transport network. However, the rapid development of the FFBSS in China has significantly increased the local municipal workload and deteriorated the public transport. To mitigate these negative impacts, the Chinese government has launched a pilot project of electronic fence spots, by selecting several bike-sharing parking spots from the existing ones to set up the virtual stations. Compared to the traditional public shared bicycles with fixed stations, the flexibility of choosing parking spots could dynamically cater the fast-changing traffic environment and facilitate the renting and returning for users and, therefore, render a more sparse and complicate parking spots network. In this paper, we study the location selection of bike-sharing parking points as a multidimensional problem, which considers not only the interests of users and stakeholders but also the environment and safety issues. We propose a multicriteria decision-making (MCDM) model including the analytic hierarchy process (AHP) and the weight-restricted data envelopment analysis (DEA) method to evaluate and determine the optimal bike-sharing parking points. Since the additional weight restrictions in the DEA method might lead to infeasible solutions, we introduce the weight restrictions feasibility theorem to avoid such infeasibility in the proposed weight-restricted DEA model, which has not been thoroughly studied in the literature. Specifically, a hyperplane adjusting model is developed to adjust the infeasible results. In the computational study, we evaluate 36 current parking spots in three regions in Beijing, China, to verify the rationality of the combined approach and put forward some managerial suggestions for this pilot project in Beijing, China.
\end{abstract}

\section{Introduction}

The bike-sharing system (BSS) is a short-time rental service system to provide customers with bikes for shared uses [1]. As a cheap, convenient, and emission-free travel method, it is suitable for small distances commuting, especially for the firstand last-mile problem in multimodal transportation in urban regions [2-4]. Although the bike-sharing programs with the earliest generation in 1965 (White Bikes, Amsterdam) have been existing for more than half a century, they recently experienced a sharp increase in their worldwide popularity along with the advent of the free-floating bike-sharing system (FFBSS). As pointed by Liu et al. [5] and Sun et al. [6], the FFBSS has more flexible parking spots locations than the traditional BSS and only requires a small area for parking, such as sidewalks, commercial plazas, residential vacancies, and other small pieces of the city. Besides, the lower construction cost and small service scope render a dense distribution of bike-sharing parking spots [7]. But, the scale-up of the bike-sharing programs may generate negative trade-offs, including abuse of public spaces and undermining long-term environmental and social sustainability in cities [8]. In the recent years, the Chinese government has launched a pilot project of electronic fence points to mitigate these negative impacts. The electronic fence points are similar to the traditional parking stations but are literally virtual stations using the Bluetooth Road Stud technology to restrict the parking regions and belong to the public infrastructures, which allow different brands of shared bikes to park in.

The selection of suitable parking spots is one of the key factors for the success of this pilot project by reducing the number of parking spots to a proper manageable level while 
satisfying the users' requirements. However, attention should be paid to the rationality of the site selection to minimize the impact of the reduction of parking spots on users. Therefore, the method prioritizing suitable locations for bike-sharing parking spots is desirable. The selection of bike-sharing parking spots is one of the facility location problems, which refers to the resource allocation optimization to choose the best location of parking spots for different objectives and constraints. Many scholars have made different attempts to solve this issue. For instance, the traditional location approach such as the P-median model and maximum coverage model [9-11], the mixed-integer linear program (MILP) $[6,12,13]$, the robust optimization method [14, 15], Data Mining [16], and GIS technique [17]. Although these methods have tackled the facility location problem efficiently to some extent, they are not suitable in a multicriteria objective optimization environment, i.e., the electronic fence selection problem, which involves operational costs, convenience, safety, and municipal management issues in the objective function. Furthermore, the selection of the appropriate electronic fence points for the FFBBS is a complex problem and requires an extensive evaluation process because it is not trivial to develop a selection criterion that can precisely describe the preference of one location over another. Besides, we will only consider deploying the electronic fence on the existing parking spots, rather than on a newly selected spot. Therefore, the selection of these sites could be viewed as a multicriteria decisionmaking $(\mathrm{MCDM})$ problem and tackled in the MCDM framework $[2,18,19]$.

The contribution of this paper is fourfold. Firstly, we propose an advanced criteria system for selecting the optimal bike-sharing parking sites with a comprehensive consideration of relevant factors, including safety, the convenience of users, the interest of companies, and the managerial difficulties, for municipal. Secondly, we justify that a hybrid approach of weight-restricted DEA and AHP with the MCDM framework could be used to solve this selection problem. Up to our knowledge, this is also the first time such a method is used in the bike-sharing spots selection problem. Thirdly, we conduct a feasibility test on the proposed approach which is not seen in pioneer studies and develop an adjusting model to modify the method. Finally, a comparative case study is provided, where we evaluate 36 current parking spots in three regions (namely, Zhongguancun Science Park, the Guomao CBD, and the Liyuan Subway Station) in Beijing, China. The comparison between the results of the basic BCC model and weight-restricted DEA is also conducted to justify the hybrid method's superiority. It not only verified the rationality of the method but also put forward some management suggestions for the pilot work in Beijing, China.

This paper is organized as follows: Section 2 reviews the literature in the evaluation and selection of bike-sharing parking spots. Section 3 introduces the advanced criteria system, the method which combines the weight-restricted DEA evaluation model with an AHP selection process and the weight restrictions feasibility theorem and the hyperplane adjusting model. A case study of several current bike- sharing spots in Beijing, China, is conducted in Section 4. The conclusions and future research directions are summarized in Section 5.

\section{Literature Review}

As mentioned by Garcia-Palomares et al. [10], the location selection of bike-sharing parking spots can be formulated as an MCDM problem, and MCDM models have been developed to assess bike-sharing stations. Kanjanakorn and Piantanakulchai [20] applied the AHP to rank suitable locations of the bike-sharing station by considering factors from the planners' and users' perspectives, such as types of land, amount of available space, accessibility to the main bike route, and walkability to destinations. Kabak et al. [2] combined the AHP and MOORA techniques with the geographic information system (GIS) to assign the priorities and rank bike-sharing stations by evaluating the conflicting criteria, which included the population, recreation areas, cycle line, and public transport networks. Among the existing MCDM techniques, i.e., the AHP, analytic network process (ANP), the technique for order of preference by similarity to ideal solution (TOPSIS), multiobjective optimization based on ratio analysis (MOORA), and DEA, the key to success is the proper decoupling points of method and reality; therefore, researchers tend to apply these methods either in a standalone fashion or in a combined way regarding the differences of real-world applications [21, 22]. Javadi et al. [19] attempted to find the best locations for bikeshare stations in the city of Isfahan using both mathematical programming and MCDM techniques. They selected four main factors of bike-sharing location such as closeness to the bicycle path, transportation and networks, and demand and used type and applied AHP to weigh these appropriate criteria. This criteria system included the measurement of the convenience and the operational cost. Then, the final weights of the proposed locations have been calculated through a simple additive weighting method. For the determination of the multicriteria system, besides cost and convenience considerations, attention to other social factors, such as safety factors and the managerial level in a station, is also crucial [23]. However, a comprehensive consideration of all these factors, to the best of our knowledge, is still rare in the literature. This paper intends to fill this gap.

Among the extensive methods to evaluate the relative efficiencies of a set of decision-making units (DMUs), DEA is an objective approach using no parametric linear programmingbased techniques and has been widely used in location selection problems, i.e., the multiple-objective layout problem completely depending on the objective data [24]. However, a subjective orientation is also important in a siting analysis whenever uncertainty, human values, or other subjectively oriented elements may play a vital part in the decision [25]. Therefore, it is desired to integrate the decision-makers' (DM) subjective judgment into the bike-sharing parking spots selection problem. The AHP approach, developed by Saaty [26], is effective when the decision-making process involves structuring multiple-choice criteria into a hierarchy to assess the "importance" weights to all the relevant decision elements, 
either objective or subjective. Yang and Kuo [27] integrated the DMs' preference into the evaluation framework by using the AHP technique to measure the qualitative factors; therefore, it leads to more efficient identification of selection criteria, weighting, and analysis.

The combination of the AHP and DEA methods integrates the subjectivity judgments and the objective selection and, therefore, renders a more accurate and reasonable result. The method of using the AHP technique to incorporate preference information into the DEA model is widely used in many situations, such as the selection of a manufacturing system for a manufacturing organization [28], the evaluation of materials [22], and the selection of optimal suppliers for the oil industry [29]. In the research area of facility location, Korpela et al. [30] combined the AHP and DEA to select the location of warehouses. Khadivi and Fatemi Ghomi [31] adopted the ANP and DEA approach in two stages to evaluate the solid waste facilities' locations. Mohajeri and Amin [18] introduced the railway station site-selection problem as a hierarchy model consisting of four levels and, then, incorporated DEA to aggregate the AHP global priorities. In most facility location researches, the AHP model is only used to generate qualitative input figures for the DEA model, where the different importance of the criteria to the system is not properly considered. To overcome this issue, we argue that the weight-restricted DEA method which has been successfully applied in many scenarios is also promising in handling the bike-sharing spot selection problem. The corresponding justification is presented in Section 3. The only paper we found that focused on a similar topic (facility location) is [32]. In their work, the authors proposed a consensusmaking method, which is based on a combination of the AHP and the assurance region (AR) model of DEA, to reach a group decision for the relocation problem of government agencies out of Tokyo. In their paper, the appropriate weights of criteria were calculated through an AHP procedure, and the additional weight constraints for the DEA model were generated by the AR technique. On the one hand, the weight restrictions of multipliers can avoid the extreme values which violate the preferences of DMs. On the other hand, this hybrid method can increase the discrimination between DMUs when the number of inputs and outputs is much larger than the number of DMUs [33]. It should be noted that additional constraints might lead to infeasible solutions to the linear programs in the DEA model [34-36]. This paper extends Takamura and Tone's [32] work by introducing an adjusted model to revise the infeasible solutions and generate reasonable results. The detailed procedure is available in Section 3.

Above all, the existing research of the bike-share parking spots evaluation criteria mainly focused on the FFBBS's productivity and users' demand. In this paper, we propose a more comprehensive criteria system to extensively describe the complex and dynamic nature of the electronic fence points selection problem. Four major criteria and eight subcriteria are identified in this system. Due to the complexity in considering the qualitative information and discriminatively quantifying the criteria, we apply a hybrid method of the AHP technique and weight-restricted DEA within the MCDM framework to streamline the evaluation process of bike-sharing parking spots locations. The AHP approach is used to assess the qualitative indicators, measure the DM's preferences among these indicators, and finally, generate additional weight restrictions to be added in the DEA method. A hyperplane adjusting model is also developed to adjust the infeasible results in the hybrid approach.

\section{Methodology}

3.1. Criteria System of MCDM. The proper identification of the criteria in the evaluation system should reflect the real-world operational scenarios and is vital to the results' rationality [4]. The evaluation criteria system should accurately assess the efficiencies of the existing bike-sharing parking points and figure out the most promising ones. An advisory board is organized to determine the criteria, which consists of three transportation engineers, two municipal planners involved in the pilot project of electronic fence points, two experts from the China Bicycle Association, three operators, and five users (the details are explained in Table 1).

After the interview with the advisory board, the factors affecting the location of bike-sharing parking spots are grouped into four main criteria, specifically, accessibility to the destination $(\mathrm{C} 1)$, walkability to the transportation hub (C2), the flexibility of bicycle renting and returning (C3), and the interest of the bike-sharing company (C4). We also reviewed the relevant literature to further examine the most influential factors of selecting bike-sharing parking spots (see Table 2). The overall explanation of the criteria is in Table 2.

(i) Accessibility to the destination (C1) includes the proximity to the destination entrance $(\mathrm{C} 11)$ and the condition of the pedestrian walkway between parking points and destinations $(\mathrm{C} 12)$. Many papers have considered the factor of $\mathrm{C} 11$; however, $\mathrm{C} 12$ is ignored by most researchers (see Table 2). The only research considered C12 [20] tackled a similar problem and argued that the pedestrian condition is an important factor that should not be neglected in cities with high population density. Good condition of the pedestrian walkway means that the passengers would get to their destinations in a fast and safe manner, while a deteriorated pedestrian walkway causes inconveniences to the passengers and prevents them from using the parking spots. Therefore, the condition of the pedestrian walkway is considered in the criteria system.

(ii) Walkability to the transportation hub (C2) consists of subcriteria such as proximity to the nearest bus stations (C21), proximity to the nearest parking spots (C22), and proximity to the nearest parking spots (C23). In large cities, bike-sharing is an important component of the "last-mile" transport to connect users to the public transit networks. It is not surprising that the first two criteria are considered in most relevant papers (as shown in Table 2). The 
TABLE 1: The members of the advisory board.

\begin{tabular}{lcc}
\hline Members & Number of experts & Working experience (years) \\
\hline Transportation engineers & 3 & $10-15$ \\
Municipal planners & 2 & 20 \\
Experts from the bicycle association & 2 & $5-8$ \\
Operators of the bike-sharing company & 3 & $5-8$ \\
Bike-sharing users & 5 & - \\
\hline
\end{tabular}

TABLe 2: Considered criteria and relation with the literature.

\begin{tabular}{|c|c|c|c|c|c|c|c|c|}
\hline & \multicolumn{2}{|c|}{$\mathrm{C} 1$} & \multicolumn{2}{|c|}{$\mathrm{C} 2$} & \multicolumn{2}{|c|}{$\mathrm{C} 3$} & \multicolumn{2}{|c|}{$\mathrm{C} 4$} \\
\hline & $\mathrm{C} 11$ & $\mathrm{C} 12$ & $\mathrm{C} 21$ & $\mathrm{C} 22$ & $\mathrm{C} 23$ & $\mathrm{C} 31$ & $\mathrm{C} 32$ & $\mathrm{C} 41$ \\
\hline Garcia-Palomares et al. [10] & $\sqrt{ }$ & & $\sqrt{ }$ & $\sqrt{ }$ & & $\sqrt{ }$ & & $\sqrt{ }$ \\
\hline Kanjanakorn and Piantanakulchai [20] & $\sqrt{ }$ & $\sqrt{ }$ & & & & $\sqrt{ }$ & $\sqrt{ }$ & \\
\hline Frade and Ribeiro [9] & & & $\sqrt{ }$ & $\sqrt{ }$ & & & & \\
\hline Murphy and Usher [37] & $\sqrt{ }$ & & $\sqrt{ }$ & $\sqrt{ }$ & & & & \\
\hline Cetinkaya [38] & $\sqrt{ }$ & & $\sqrt{ }$ & $\sqrt{ }$ & & $\sqrt{ }$ & & $\sqrt{ }$ \\
\hline Kabak et al. [2] & $\sqrt{ }$ & & $\sqrt{ }$ & $\sqrt{ }$ & & $\sqrt{ }$ & & $\sqrt{ }$ \\
\hline This paper & $\sqrt{ }$ & $\sqrt{ }$ & $\sqrt{ }$ & $\sqrt{ }$ & $\sqrt{ }$ & $\sqrt{ }$ & $\sqrt{ }$ & $\sqrt{ }$ \\
\hline
\end{tabular}

distance to the nearby parking spots represents the service radius of the parking spots and also indicates the time a customer should expect to find a parking spot. Besides, the setup cost of a parking spot renders high operational expenses for intensive parking spots deployment. Therefore, C23 is also an important indicator explaining the tradeoff between service quality and capital investments and deserves its right to be considered in the criteria system.

(iii) Flexibility of bicycle renting and returning (C3) is a factor measuring the conveniency for users to retrieve the bicycles. The proximity to the bike lane (C31) denotes the distance to the bike lane and the corresponding riding quality. It is often used to describe the safety and the convenience of riding a bike. The amount of available space (C32) indicates the size of the area and the number of bicycles which can be parked. It should be noted that, during the rush hours (i.e., 7-9 am), insufficient parking space might force a customer to find an undesirable place, i.e., a far-way parking spot, pedestrian, or shrubs beside the road, to park his/her bikes. The imbalances between bikeholding amount and dynamic bike requirements in different stations often lead to a shortage of bikes or lack of parking space. Besides, a parking spot of the large size normally needs a large amount of investment and much managerial effort. All these issues require a dedicated study on determining the size of each parking spot. Therefore, C32 is included in our study as well.

(iv) The interest of the bike-sharing company (C4) is reflected by the population density (C41). For private businesses, a high turnover rate of bikes is vital to maintain a healthy business. It is reasonable to locate the parking spot in the area with a high volume of population.
The overall criteria system is summarized in Figure 1. Considering the different priorities of criteria, an AHP approach is applied to determine the weight coefficient of each criterion. The methodology of the AHP in this study follows Subramanian and Ramanathan's [39] research, and we put the detailed procedure in Appendix A.

3.2. Weight-Restricted DEA Models. For basic BCC models (shown in Appendix B), the multipliers of inputs $(u)$ and outputs $(v)$ are derived from the data instead of being fixed in advance. In the AHP tree for bike-sharing parking spots selecting, the importance of each input indicator is not equal. Without the restrictions of multipliers, it may cause tremendously large or small weights for some criteria whereas these extreme values are undesirable considering the DMs' preference. Besides, a large number of input and output indicators in the evaluation framework would cause an overestimation of the parking spot's efficiency. The usage of weight-restricted DEA is not only to incorporate the preference information into the basic DEA method but also to diversify the discrimination between DMUs when the number of inputs and outputs is much larger than the number of DMUs. Stawicki and Lawrence [40] compared the DEA with and without weight restrictions, respectively. Finally, they concluded that when the weighting given to the various inputs and outputs is forced into a narrow band across all factors, their efficiency drops off significantly.

There are many methods for incorporating DMs' value judgment in DEA assessments [41]. Allen et al. [33] concluded that the incorporation approaches are very application-driven: in real-world applications, there have emerged situations where some preference information is needed, and this has dictated the way it has been incorporated. We divide the methods into three categories and specify the applications using each approach, see Figure 2.

Direct weight restrictions could be the absolute upper and lower bounds on the weights proposed by Roll et al. [47]. 


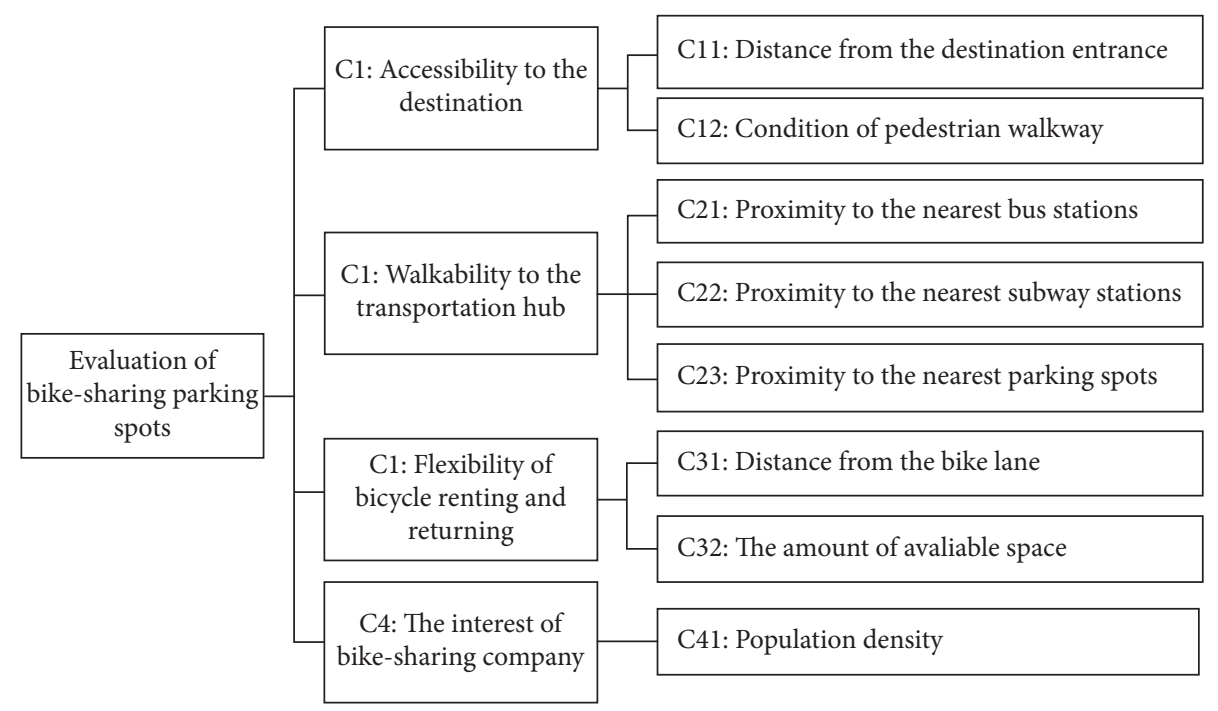

FIgURE 1: Proposed criteria system.

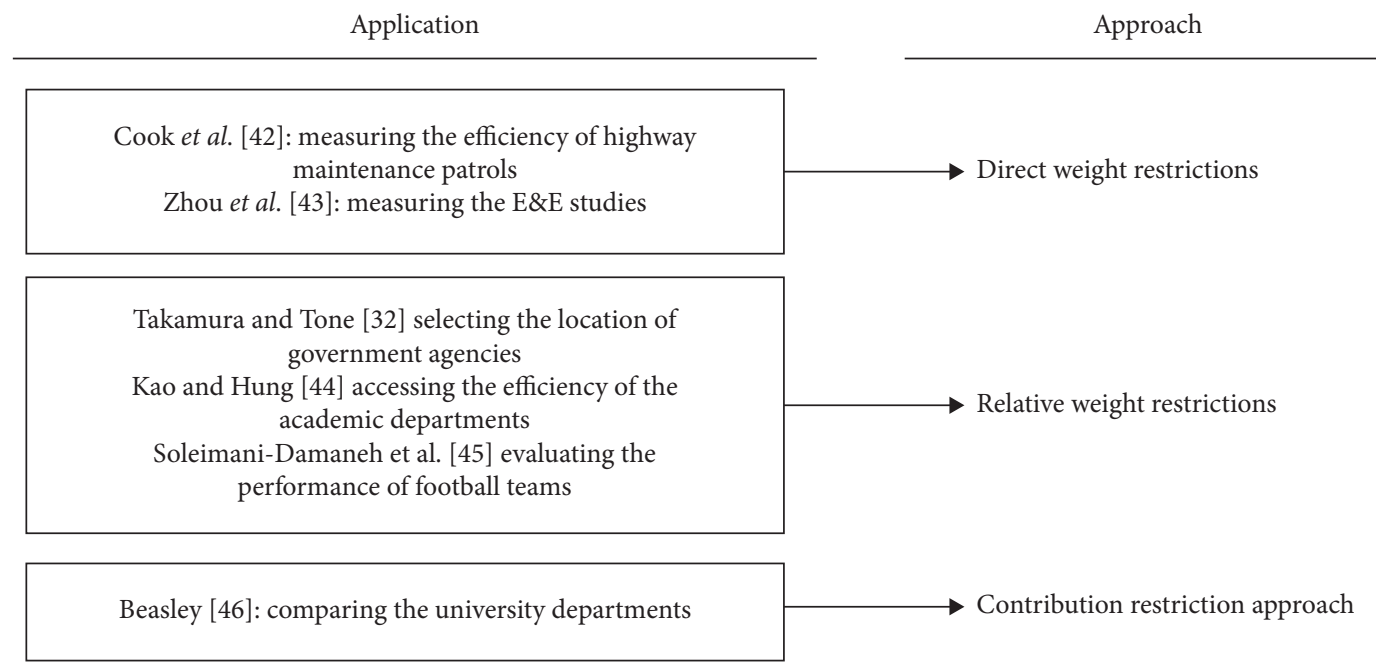

FIgURE 2: Approach for incorporating value judgments in DEA [42, 43].

Since the magnitude of the weights in the direct weight restrictions depends on the scale of the inputs and the outputs, it is difficult and unintuitive for a DM to find the restrictions that capture his/her preferences [48]. In the contribution restriction approach, which was firstly introduced by Wong and Beasley [49], the lower and upper bounds are placed to the contribution of each input and/or output. However, this weight-restriction scheme could lead to more additional restrictions. Due to the computational expensiveness of the contribution restriction approaches, we utilize the relative weight restrictions AR to incorporate the DMs' preferences into the location selection problem [50]. The idea of this approach is to restrict the relations of weights of the inputs and/or outputs and to exclude virtual multiplier vectors that are not reasonable from the model $[32,45,51,52]$. In this paper, the AR is specified by the AHP method. We mainly reference the procedure of SoleimaniDamaneh et al.'s [45] paper, which calculated the ratios of other outputs/inputs weights and the weight of the first output/input. In this paper, we only consider the relative ordering or values of the multi-input factors because of the brief components of outputs, such as user satisfaction and the bike-sharing turnover rate.

We add the restrictions $A v \leq 0$ into the input-oriented BCC model (see equation (B.1) to (B.4) in Appendix B). The envelopment form (dual) of the weight-restricted DEA model is as follows:

$$
\begin{gathered}
\min \quad h, \\
\text { s.t. } \quad X_{0} h-X \lambda+A^{T} \gamma \geq 0, \\
-Y_{0}+Y \lambda \geq 0, \\
1^{T} \lambda=1,
\end{gathered}
$$




$$
\lambda \geq 0,
$$

where $A$ is a $p \times n$ matrix and $\lambda$ and $\gamma$ are the dual vectors.

3.3. Models to Test the Feasibility. Note that adding the weight boundaries to the DEA model might lead to infeasible DEA evaluations. Chang and Wang [53] pointed out two shortcomings of AHP restrictions: the subjectivity and inconsistency of dating the AHP in DEA and the local optimality of DEA. To overcome the probabilities of infeasible DEA results, the methods to avoid inefficiency are discussed in many papers. For instance, Podinovski [48] proposed a maximum DEA model to avoid the side effects of incorporating absolute weight bounds, and it is equivalent to the classical DEA model if no additional restrictions are imposed. Lins et al. [34] proposed the weight restrictions feasibility theorem to test the feasibility of the results and, then, introduced the adjusting models to modify the results. In this paper, we utilize the weight restrictions feasibility theorem given by Lins et al. [34] to test whether the BCC models are still feasible after adding the weight restrictions.

Theorem 1. If there exists no vector $\gamma \geq 0$ such that $A^{T} \gamma>0$, then conditions $A v \leq 0$ are met and the weight-restricted DEA model is feasible.

Theorem 2. Instead, if there exists a vector $\gamma \geq 0$ such that $A^{T} \gamma>0$, then conditions $A v \leq 0$ are not met and the weightrestricted DEA model is infeasible.

Proof. For envelopment program equations (1) to (5), we suppose that $\forall \gamma \geq 0$ and there exists, at least, one row $k$ of $A^{T}$ which makes $\left(A^{T}\right)_{k}^{*} \gamma \leq 0$. For constraint (2) we have $X_{0 k} h \geq X_{k} \lambda-\left(A^{T}\right)_{k} \gamma$. Therefore, the variable $h$ to be minimized has the lower bound, which means the weight-restricted model is feasible. Conversely, suppose $\exists \gamma \geq 0$ such that $A^{T} \gamma>0$. $\gamma$ is not bounded, then $A^{T} \gamma$ is not bounded as well. Thus, $h$ has no lower bound, which means this model is infeasible.

If we find one $\gamma$ to make $A^{T} \gamma>0$, we need to relax the weight bounds by using the adjusted weight matrix $A-A^{\prime}$. The hyperplane adjusting model with the objective of finding the minimum loosening adjustments is as follows:

$$
\begin{array}{ll}
\min & 1^{T} A^{\prime} 1, \\
\text { s.t. } & \left(A-A^{\prime}\right) v \leq 0, \\
& v, A^{\prime} \geq 0,
\end{array}
$$

where $A$ is the upper bound assigned to the ratio of two input indicators, $A^{\prime}$ is the adjustment matrix, and 1 is a column unit vector.

The process of the proposed methodology solving the parking spots selection problem is illustrated in Figure 3. There are five main steps in our procedure, such as the determination of criteria, the collection, construction of the database (qualitative data and qualitative data, respectively), calculating for the current parking spots using this hybrid AHP-DEA approach, testing for the feasibility of our models and adjusting the infeasible results, and ranking for the alternative parking spots. We will use this procedure in the case study.

\section{Case Study}

In this section, we conduct a case study on three selected regions in Beijing, China. The proposed hybrid AHP-DEA method is applied to process the collected data. We also provide a comparison between this hybrid approach and the conventional method and managerial insights to the parking spots selection problem during the electrical fence deployment campaign.

4.1. Region Selection. Beijing is the capital city of China and is one of the largest cities in China with approximately 21.5 million inhabitants. In 2019, the average daily bike-sharing ride volume in Beijing reached to 1.272 million times, and the average daily turnover rate was 1.4 times per vehicle (Beijing Municipal Commission of Transport). The Beijing Municipal Government has launched the first batch of electronic fence points in three districts: Haidian, Chaoyang, and Tongzhou. The heat map of riding demand in the urban region is shown in Figure 4 (OFO big data). Haidian district is located in the northwest part of Beijing with a greater demand for bike-sharing in the heat map. Chaoyang district has the largest area in the downtown and is located in the east part of the urban area with a moderate riding demand. To the east of Chaoyang district is the Tongzhou district with less demand for cycling. In this study, three different regions from the abovementioned districts are selected as the testbeds of our evaluation approach (the three red circles depicted in Figure 4).

Considering the small service scope, relatively dense layout, and wide range of bike-sharing parking points, the analysis of parking spots' efficiency should focus on the riding routes in the bike-sharing system, i.e., between parking points and destinations [20]. Besides the conventional method dividing the target regions by the volume of riding demand (Large, Medium, and Small), we distinguish the regions by their surroundings as well (shopping malls, residential area, and so on). The purpose is to evaluate the effectiveness of our hybrid method and extend the boundaries of our research. These selected regions are all with high population mobility, namely, Zhongguancun Science Park, the Guomao CBD, and the Liyuan Subway Station, as shown in Figures 5-7, respectively. The features of these three small regions are described in Table 3.

In each region, 12 bike-sharing parking spots are selected (in total 36 spots). The selection of these spots is mainly based on the current bike-sharing networks. The index and location of each spot is illustrated in Figures 5-7. The AHP method is applied to calculate the weights of criteria with regard to the DMs' preference. The obtained weights are, then, incorporated into the weightrestricted DEA model to rank the parking points in each zone. 


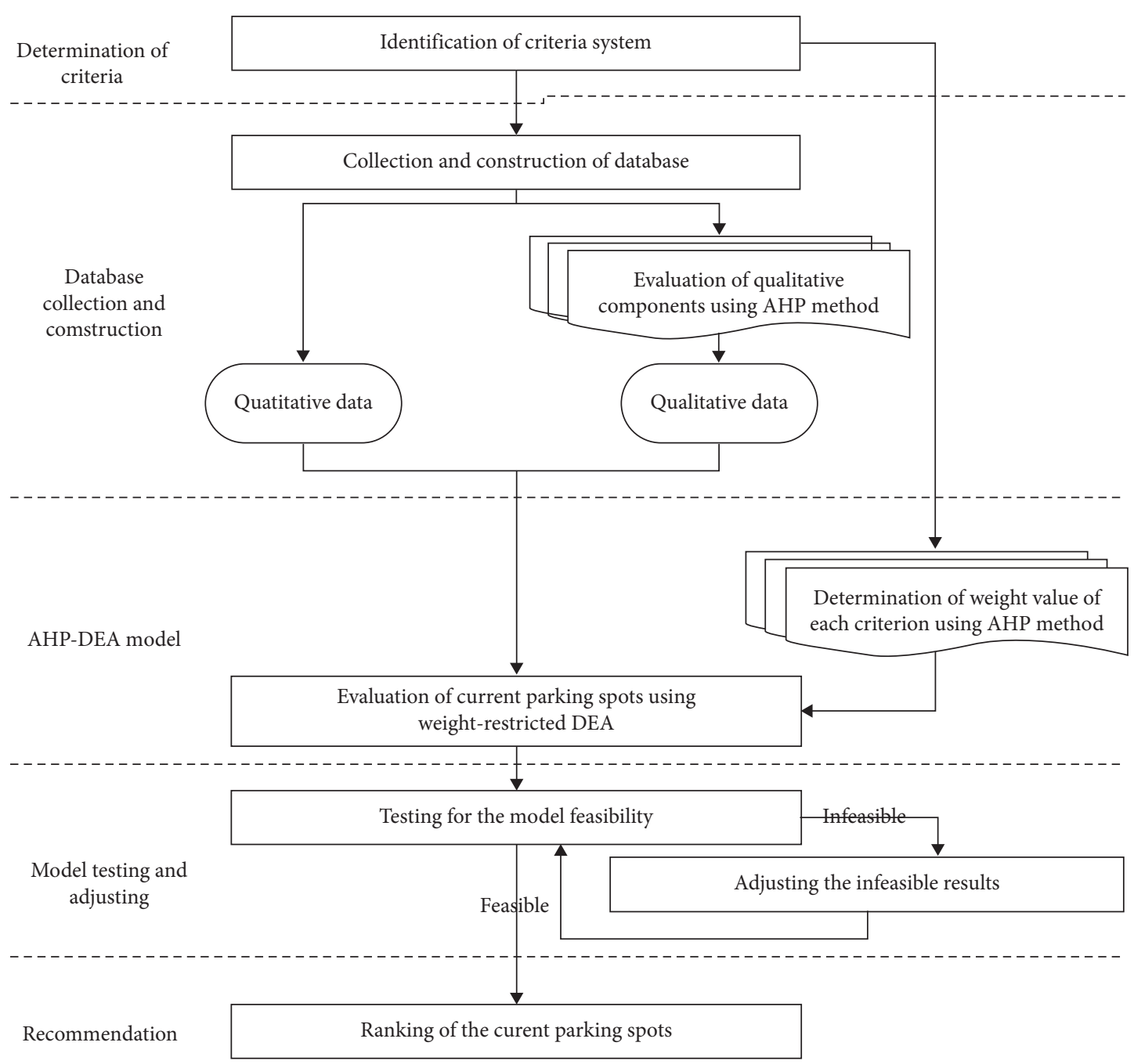

Figure 3: Methodology for the spots selection process.

4.2. Data Processing and Calculating. The data of input factors C11, C21, C22, C23, C31, and C32 are obtained from the investigation in the field. The qualitative factors C12 and C31 are assessed by the AHP technique. C41 is extracted from the Geographical Information Monitoring Cloud Platform (China). For the output factors, we consider the user satisfaction (O1) and bike-sharing turnover rate $(\mathrm{O} 2)$. $\mathrm{O} 1$ is acquired based on a questionnaire survey. Note that, to supplement the interview data, additional data from a variety of sources, including business and media reports, were also utilized. $\mathrm{O} 2$ is the volume changes of bicycles in one specific parking point between two consecutive observation periods and is obtained from the investigation in the field.

In this study, the members of the advisory board are required to make pairwise comparisons by using questionnaire and face to face interview to determine the relative importance of the input factors. The question is like "how do criterion A and B relatively differ in importance?" Super Decisions V2.10 for Mac is used to calculate the results. Afterward, we calculate the geometric mean for the experts' opinions, and the values are collected in Table 4 . The CR value is less than 0.1 , which means the data comparing the criteria pairs is appropriate and does not need to be re-evaluated.

As we can observe from Table 4, the most significant factors concerned by the members of the advisory board in locating bike-sharing parking spots are the proximity to the bus stations and subway stations (both with $w=0.2175)$ and the population density $(w=0.1706)$. The proximity to the bike lane $(w=0.0396)$, the condition of pedestrian walkway $(w=0.0460)$, and the amount of available space $(w=0.0649)$ are less important factors from the aspect of FFBSS operations. According to these values, we impose the weight restrictions using the AR I weighting scheme, where weights of the other inputs are related to the weight of the first input. This procedure is also proposed in the work of Joro and Korhonen [41] and Soleimani-Damaneh et al. [45]. The resulting weight matrix $A$ is as follows: 


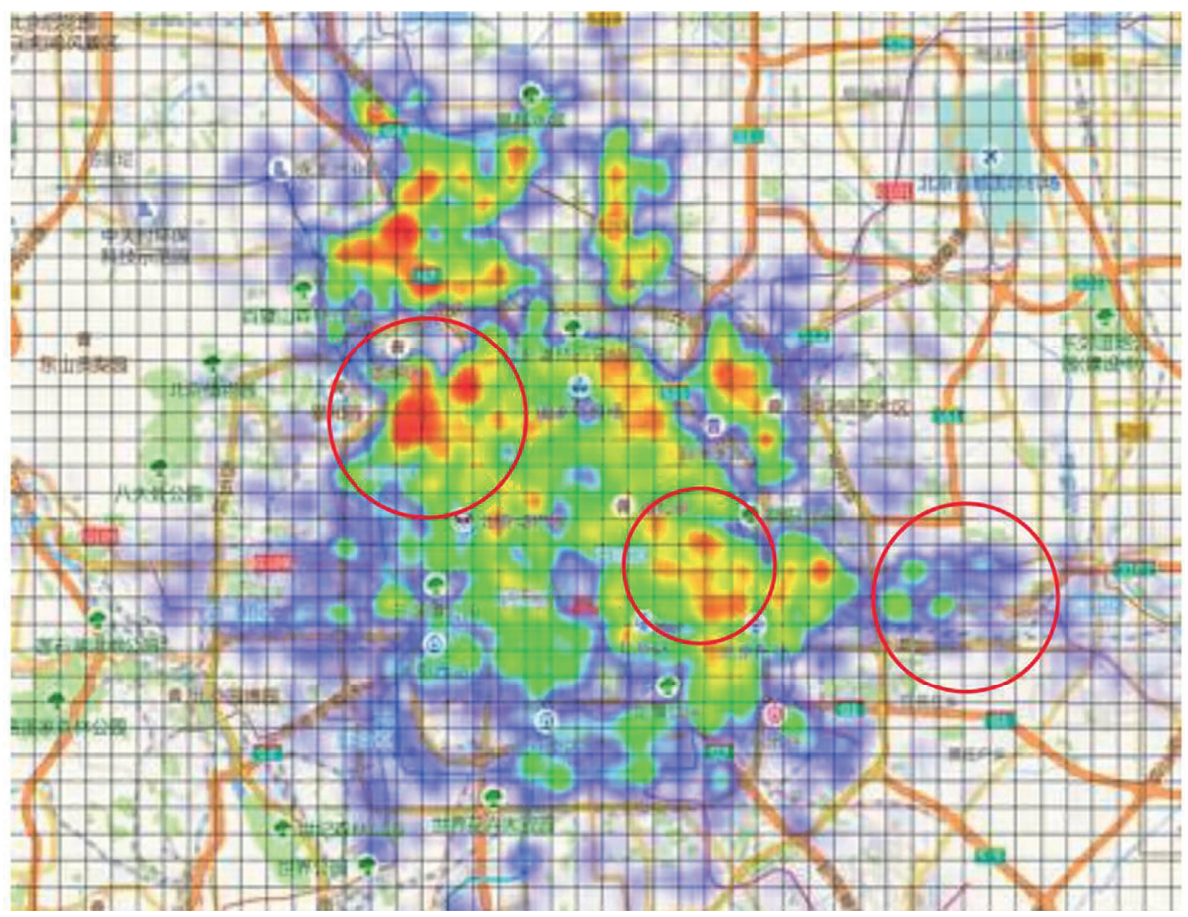

Figure 4: The heat map of riding demand in Beijing.

$$
A=\left[\begin{array}{cccccccc}
1 & -3 & 0 & 0 & 0 & 0 & 0 & 0 \\
-2 & 0 & 1 & 0 & 0 & 0 & 0 & 0 \\
-2 & 0 & 0 & 1 & 0 & 0 & 0 & 0 \\
-1 & 0 & 0 & 0 & 1 & 0 & 0 & 0 \\
-1 & 0 & 0 & 0 & 0 & 3 & 0 & 0 \\
-1 & 0 & 0 & 0 & 0 & 0 & 2 & 0 \\
1 & 0 & 0 & 0 & 0 & 0 & 0 & -1
\end{array}\right] .
$$

Adding the input weight constraints $A v \leq 0$ to the basic BCC model, we would obtain the weight-restricted DEA scores, as shown in the fourth column of Tables 5-7. The basic BCC scores are listed in the second column for the sake of comparison.

To verify the feasibility of the evaluation, we test the results using the weight restrictions feasibility theorem described in Section 3.3. We observe that there is no vector $\gamma>0$ making $A^{T} \gamma>0$, which means the result is feasible.

4.3. The Comparison of Basic BCC Results and Weight-Restricted DEA Results. In Tables 5-7, the rankings of the evaluations scores based upon the obtained efficiency scores are summarized in the third and fifth column of these three tables. It can be observed that 9 parking spots (75\%) in Zhongguancun Science Park have efficiency score equal to 1, and the value for the Guomao CBD and Liyuan Subway Station is $7(58 \%)$ and $9(75 \%)$, respectively. This means that most points are on the efficient frontier. The overestimation of efficiency scores relies on the large number of input and output factors in the DEA framework. In the conventional evaluation procedure, the number of DMUs is normally two times more than the number of input and output factors [41]. The addition of the weight restrictions into the BCC model would decrease the efficiency scores of most DMUs, as shown in Figure 8. This is one of the advantages of weightrestricted DEA, which can increase the discrimination between DMUs when the number of inputs and outputs is much larger than the number of DMUs.

Furthermore, we can find that the efficiency average considering the DMs' preferences in the Guomao CBD (0.8867) is less than the efficiency average in Zhongguancun Science Park (0.9295) and the Liyuan Subway Station (0.9347). However, without the consideration of the criteria priority, Zhongguancun Science Park has the lowest efficiency average and the DMs' preferences have the largest impact.

The efficiency score of spot 1 changes from 1 to 0.9396 . The high score in the BCC model is due to the short distance from the subway station, while it is far from the destination entrance than the other alternatives. The distance from the destination entrance is considered as one of the most important factors for the evaluation (see Table 4). The same reason explains the score changes of spot 10, which is near the gate of community and is close to the nearest parking spots. However, it is far from the subway stations and the bus stations. For spot 13-24, all of them are far away from the subway stations and bus stations.

After adding the weight restrictions to the basic BCC model, six spots have a lower efficiency score. Among them, spot 21 changes from the performance-efficient to the inefficient. That is because it has the smaller population density, which is a major influential factor for the selection of electronic fence spots. The efficiency score of spot 23 changes from the rank of 10 to the rank of 8 . The small population density renders a lower score, while the short 


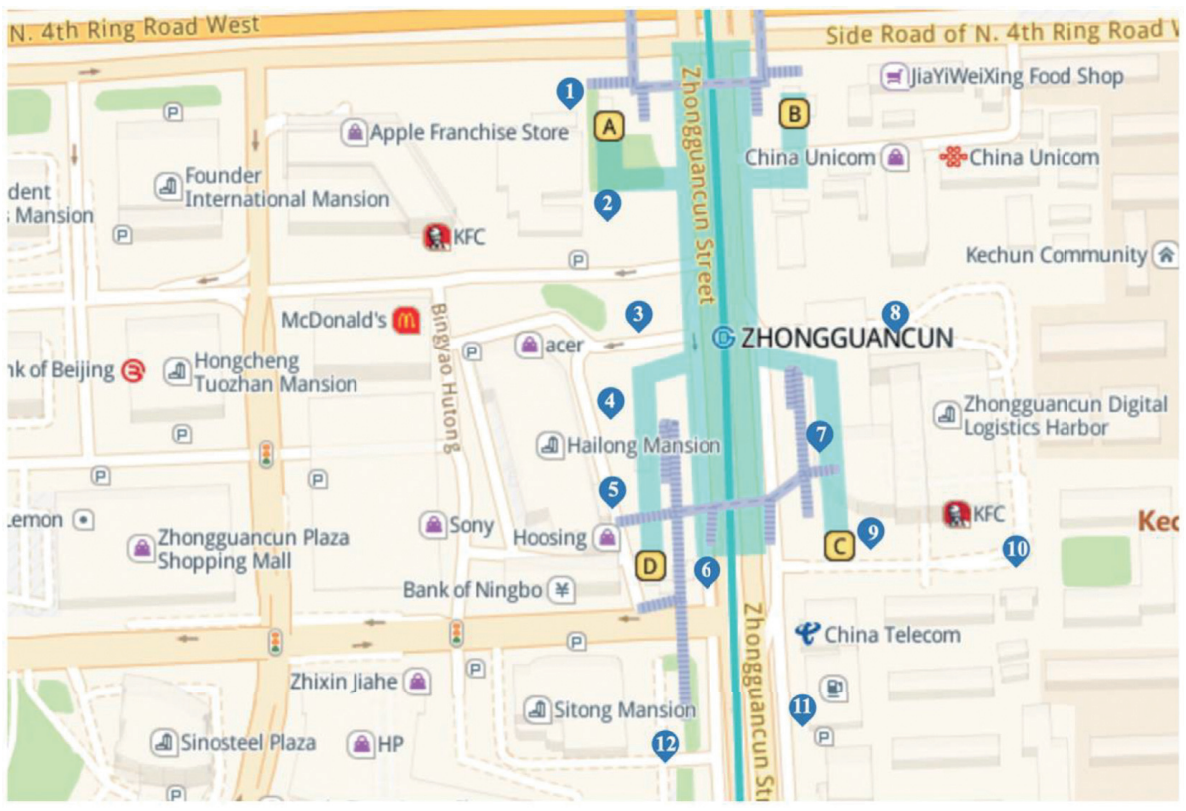

FIGURE 5: Twelve current bike-sharing parking spots in Zhongguancun Science Park.

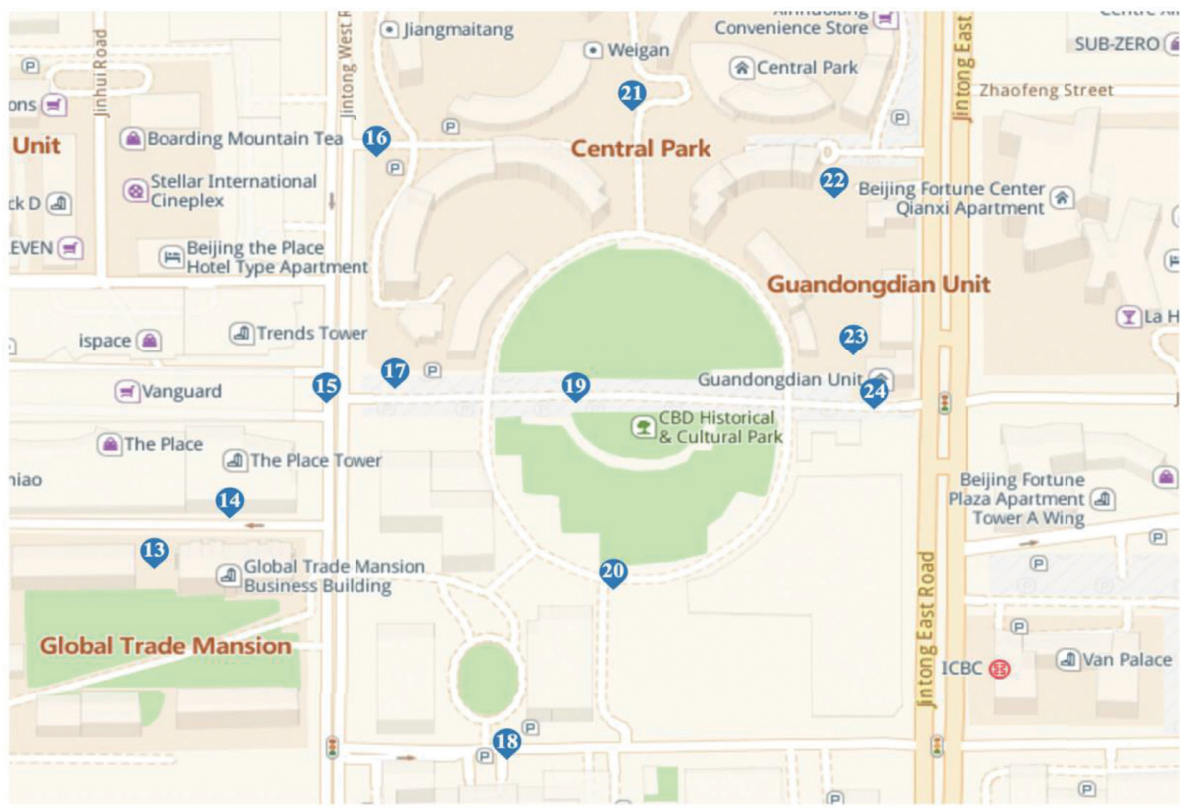

FIgURE 6: Twelve current bike-sharing parking spots in the Guomao CBD.

distance from the destination entrance and parking spots raises its ranking. For the efficiency scores of spot 25-36, there are only 4 spots, including spot 27 , spot 30 , spot 33 , and spot 36, on the efficiency frontier, when different importance of the input indicators are considered. Although the spot 25 is close to the destination entrance, its rank drops significantly because of its long distance from the subway station.

Spot 4 (in Zhongguancun Science Park), spot 20 (in the Guomao CBD), and spot 26 (near the Liyuan Subway Station) have the lowest rank. That is because all of them have a small population density. From Figure 8, we can see that spot 32 has the least changes. That is because the worst input factor is the condition of the pedestrian walkway, which is considered in the 7 th place among the eight input factors.

From the abovementioned analysis, we find out that adding weight restrictions into the DEA framework is an effective method to integrate the DM's preference information. The unacceptable value could be avoided. However, we could not 


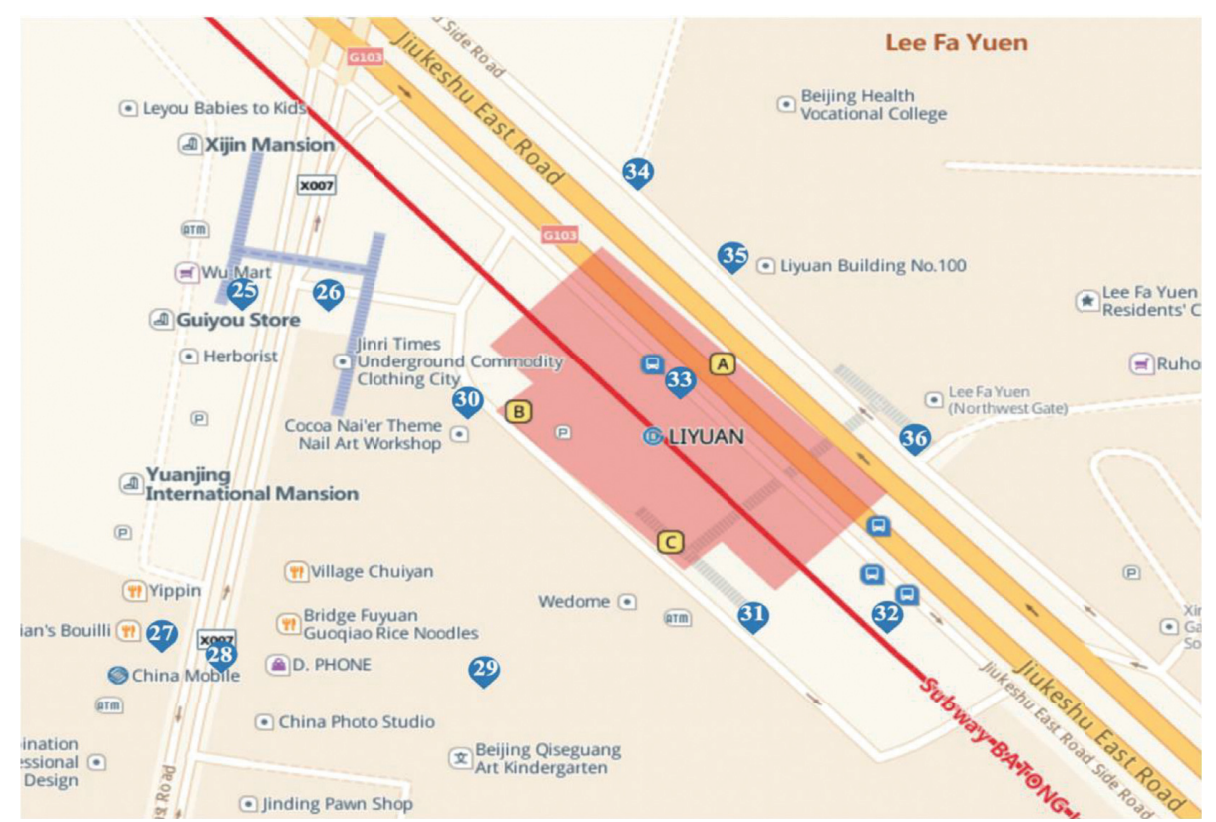

Figure 7: Twelve current bike-sharing parking spots near the Liyuan Subway Station.

TABLE 3: The feature of these three places.

\begin{tabular}{lccc}
\hline & District & Riding demand & Surrounding \\
\hline Zhongguancun Science Park & Haidian district & Large & Commercial buildings, shopping mall, hospital, and university \\
Guomao CBD & Chaoyang district & Medium & Shopping mall, residential area, park, and commercial buildings \\
Liyuan Subway Station & Tongzhou district & Small & Residential area, university, hospital, and shopping mall \\
\hline
\end{tabular}

TABle 4: The weights of different input factors.

\begin{tabular}{lcc}
\hline Input factors & Weights & Ranks \\
\hline Distance from the destination entrance & 0.1338 & 4 \\
Condition of the pedestrian walkway & 0.0460 & 7 \\
Proximity to the bus stations & 0.2175 & 1 \\
Proximity to the subway stations & 0.2175 & 0.1102 \\
Proximity to the parking spots & 0.0396 & 5 \\
Distance from the bike lane & 0.0649 & 8 \\
The amount of available space & 0.1706 & 3 \\
Population density & & \\
\hline
\end{tabular}

TABLE 5: The efficiency scores of spots 1 to 12.

\begin{tabular}{lcccc}
\hline DMU & Basic BCC scores & Ranks & Weight-restricted DEA scores & Ranks \\
\hline Spot 1 & 1 & 1 & 0.9396 & 1 \\
Spot 2 & 1 & 1 & 1 & 1 \\
Spot 3 & 1 & 1 & 0.6773 & 1 \\
Spot 4 & 0.6894 & 12 & 1 & 12 \\
Spot 5 & 1 & 1 & 1 & 1 \\
Spot 6 & 1 & 1 & 1 & 1 \\
Spot 7 & 1 & 1 & 1 & 1 \\
Spot 8 & 1 & 1 & 0.9789 & 1 \\
Spot 9 & 1 & 1 & 0.8449 & 8 \\
Spot 10 & 1 & 10 & 0.6925 & 1 \\
Spot 11 & 0.9022 & 11 & 0.9295 \\
Spot 12 & 0.7460 & & 11 \\
\hline Average & 0.9448 & & 1 \\
\hline
\end{tabular}


TABle 6: The efficiency scores of spots 13 to 24 .

\begin{tabular}{|c|c|c|c|c|}
\hline $\mathrm{DMU}$ & Basic BCC scores & Ranks & Weight-restricted DEA scores & Ranks \\
\hline Spot 13 & 0.8496 & 11 & 0.5706 & 11 \\
\hline Spot 14 & 0.9958 & 8 & 0.7660 & 10 \\
\hline Spot 15 & 1 & 1 & 1 & 1 \\
\hline Spot 16 & 1 & 1 & 1 & 1 \\
\hline Spot 17 & 1 & 1 & 1 & 1 \\
\hline Spot 18 & 0.9734 & 9 & 0.8982 & 9 \\
\hline Spot 19 & 1 & 1 & 1 & 1 \\
\hline Spot 20 & 0.5647 & 12 & 0.5017 & 12 \\
\hline Spot 21 & 1 & 1 & 0.9884 & 7 \\
\hline Spot 22 & 1 & 1 & 1 & 1 \\
\hline Spot 23 & 0.9632 & 10 & 0.9155 & 8 \\
\hline Spot 24 & 1 & 1 & 1 & 1 \\
\hline Average & 0.9456 & & 0.8867 & \\
\hline
\end{tabular}

TABLE 7: The efficiency scores of spots 25 to 36.

\begin{tabular}{lcccc}
\hline DMU & Basic BCC scores & Ranks & Weight-restricted DEA scores & Ranks \\
\hline Spot 25 & 1 & 1 & 0.9061 & 9 \\
Spot 26 & 0.7736 & 12 & 0.6467 & 1 \\
Spot 27 & 1 & 1 & 0.8741 & 1 \\
Spot 28 & 0.9407 & 10 & 0.9872 & 1 \\
Spot 29 & 1 & 1 & 1 & 6 \\
Spot 30 & 1 & 1 & 0.9801 & 1 \\
Spot 31 & 1 & 1 & 0.9934 & 7 \\
Spot 32 & 1 & 1 & 1 & 5 \\
Spot 33 & 1 & 1 & 0.9645 & 1 \\
Spot 34 & 1 & 1 & 0.8646 & 1 \\
Spot 35 & 0.8895 & 11 & 1 & 1 \\
Spot 36 & 1 & 1 & 0.9347 \\
\hline Average & 0.9670 & & & 1 \\
\hline
\end{tabular}
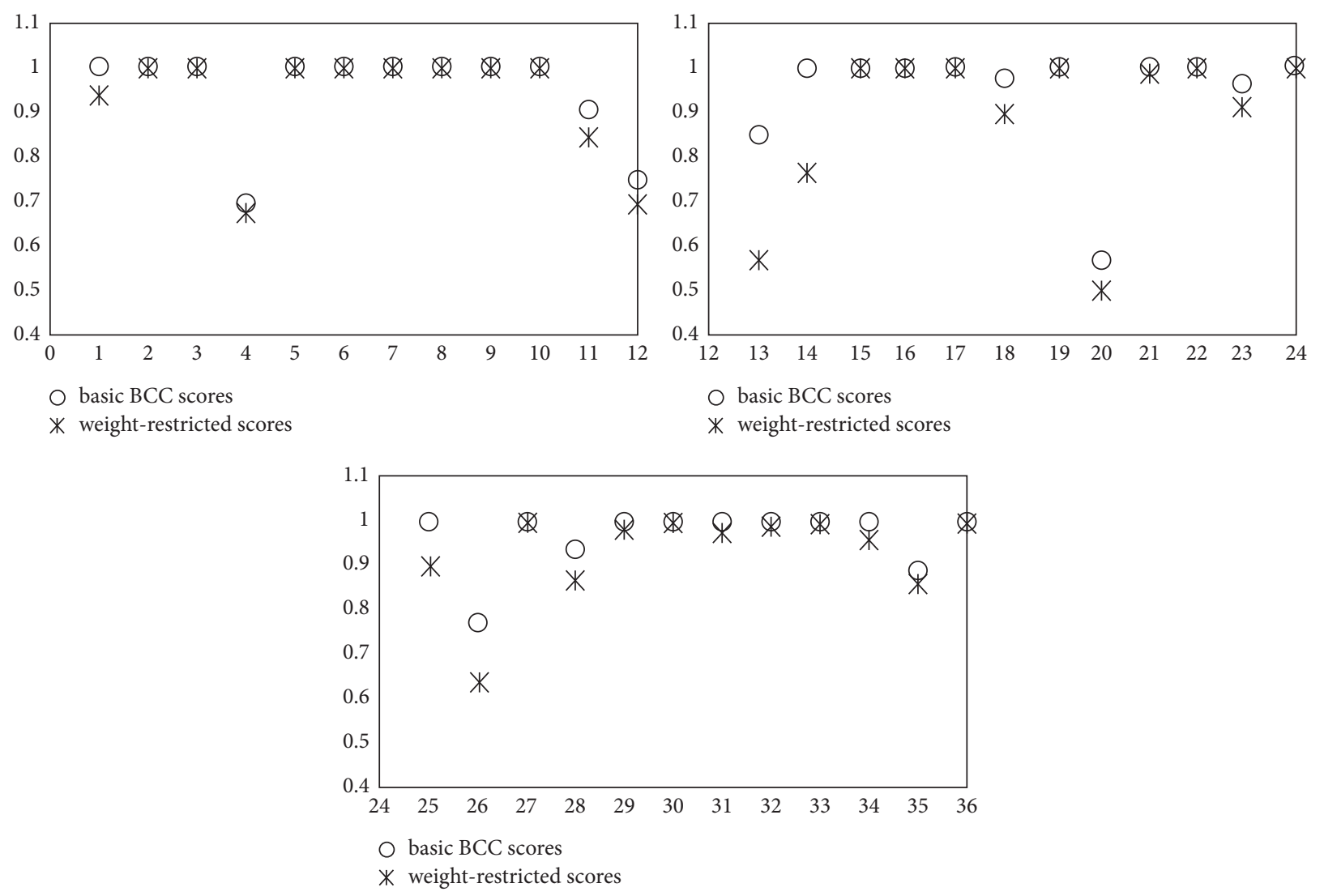

Figure 8: Result analysis. 


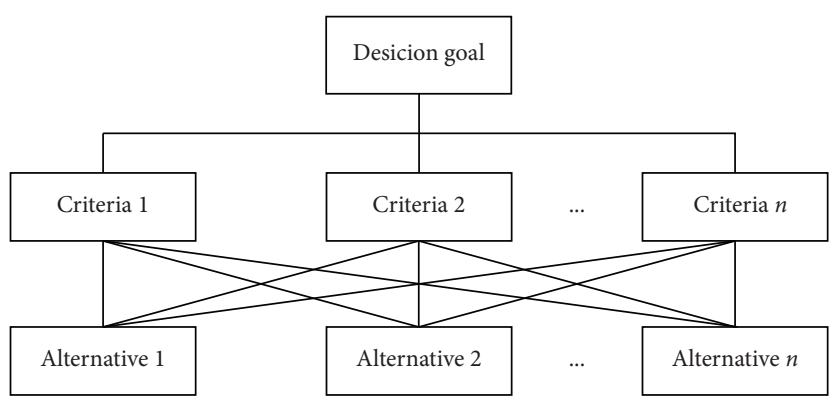

Figure 9: The hierarchy analysis tree.

rank the points with an efficient score of 1 in this model. In future work, we could utilize the method such as super DEA to overcome the deficiencies.

4.4. The Managerial Suggestions. For the final design, we suggest that the municipal planners can select the spots with high scores to build the virtual sites in the certain regions.

Nearing Zhongguancun Science Park, there are seven spots, spot 2, 3, and spot 6 to 10 on the efficiency frontier by incorporating the DMA' preference. It means that these spots are more efficient than the others. Besides, nine spots have the larger scores than the average efficient scores. This implies that the Beijing municipal could choose these spots to setup the electrical fences. In the region of the Guomao CBD, spot 15, 16, 17, 19, 22, and 24 are the efficient spots. Eight spots have the higher scores than the average. Across the Liyuan Subway Station, there are four alternative spots with the efficient score of 1 and eight spots above the average level of the twelve alternatives. All of these results have considered the multiple factors as we 2 have mentioned in Section 3.

\section{Conclusions}

Bike-sharing parking points evaluation and selection have been identified as an important problem that can affect the efficiency of company operation and social warfare. It can be seen that selecting a parking space is a complicated problem, and DMs must have a wide view concerning qualitative and quantitative features to assess the symmetrical impact of the criteria to reach the most accurate result.

In this paper, four main criteria and eight subcriteria were determined by extensive literature examination and the insights of experts. The AHP was applied to obtain the weights of the criteria, as expected, and the proximity to the public traffic network and the population density were determined to be more important than other criteria. Besides, the AHP technique was also used to obtain the quality input factors. Then, the weight-restricted DEA using the AR I weighting scheme, which obtained from the AHP result, was proposed to evaluate the current bikesharing parking spots in the final stage. Finally, 36 current parking spots near Zhongguancun Science Park, the Guomao CBD, and the Liyuan Subway Station were evaluated by using the combined method. From the results, we can find that not all the current parking sites are efficient in the performance. When DMs give a different performance in the evaluation factors, the alternatives will get different performance scores. This research also presents useful guidelines for layout optimization processes in other situations.

The hybrid method proposed in this paper cannot effectively rank the DMU if the efficiency value is 1 . For example, there are seven spots at the rank of 1 near Zhongguancun Science Park. In future work, it would be interesting to adopt the superefficiency DEA or other methods to tackle this problem.

\section{Appendix}

\section{(A). AHP Method}

The process of applying the AHP is divided into the following four steps:

(i) Step 1. Constructing the hierarchy analysis trees

The hierarchy analysis tree is shown in Figure 9. There are three layers such as the target layer, the criteria layer, and the alternative layer.

(ii) Step 2. Building the pairwise comparison judgment matrices

The pairwise comparison matrix $B$, in which the element $b_{i j}$ of the matrix is the relative importance of the $i_{\text {th }}$ factor with respect to the $j_{\text {th }}$ factor, is constructed by DMs and experts according to the scale given in Table 8.

$$
B=\left[\begin{array}{cccc}
1 & b_{12} & \cdots & b_{1 n} \\
1 / b_{12} & 1 & \cdots & b_{2 n} \\
\vdots & \vdots & \cdots & \vdots \\
1 / b_{1 n} & 1 / b_{2 n} & \cdots & 1
\end{array}\right] .
$$

(iii) Step 3. Determining the weights of decision elements

The eigenvector method is used to yield priorities for criteria and for alternatives by criteria. 
TABLE 8: Pairwise comparison scale.

\begin{tabular}{lc}
\hline $\begin{array}{l}\text { Scale of } \\
\text { importance }\end{array}$ & Interpretation \\
\hline 1 & Equal importance \\
3 & Moderate importance \\
5 & Strong importance \\
7 & Very strong or demonstrated \\
9 & importance \\
$2,4,6,8$ & Extreme importance \\
& For compromise between the \\
& abovementioned values \\
\hline
\end{tabular}

TABLE 9: Average random consistency random index.

\begin{tabular}{lcccccccccc}
\hline$n$ & 1 & 2 & 3 & 4 & 5 & 6 & 7 & 8 & 9 & 10 \\
\hline $\begin{array}{l}\text { Random } \\
\text { consistency }\end{array}$ & 0 & 0 & 0.58 & 0.9 & 1.12 & 1.24 & 1.32 & 1.41 & 1.45 & 1.49 \\
\hline
\end{tabular}

$$
B W=\lambda_{\max } W
$$

where $\lambda_{\max }$ is the largest eigenvector and $W$ is the weight vector. Note that we need to normalize $W$ after calculating.

(iv) Step 4. Checking the consistency

We need to calculate the Consistency Ratio (CR) of each used pairwise matrix to make sure their values are less than 0.1 .

$$
\mathrm{CR}=\frac{\mathrm{CI}}{\mathrm{RI}}
$$

Consistency Index (CI) is the consistency of the judgment matrix and is defined as follows:

$$
\mathrm{CI}=\frac{\lambda_{\max }-n}{n-1}
$$

where $n$ is the size of the matrix and Random Index (RI) is the average random consistency random index, as shown in Table 9.

\section{(B). Basic BCC Model}

Data envelopment analysis (DEA) is the linear programming (LP) technique that converts multioutput and multi-input into a scale measure of efficiency. It is suitable for the case of evaluating the current FF-BBS parking spots. The DEA model was originally proposed by Charnes et al. [54], which assumes a constant return to scales (CRS) called the CCR model. Banker et al. [55] extended the CCR model by adding the convexity constraint $1^{T} \lambda=1$ to account for variable returns to scale (VRS), called the BCC model.
The multiplier form of the input-oriented BCC model is as follows. Assume that there are $s$ DMUs, with each DMU producing $m$ outputs by using $n$ inputs. $Y$ is the $m \times s$ output matrix, and $X$ is the $n \times s$ input matrix. $Y_{0}$ and $X_{0}$ are the vectors of the DMU being evaluated. The $m \times 1$ vector $u$ and the $n \times 1$ vector $v$ are the flexible weights for outputs and inputs separately. $u_{*}$ is the correspondent dual variables of the convexity constraint $1^{T} \lambda=1$ (where $\lambda$ is an intensity vector, " 1 " on the left hand is a $s \times 1$ vector, and 1 on the right hand is a scalar). The symbol 1 in equation (B.2) is a scalar and is a $s \times 1$ vector in equation (B.3). The objective is to obtain the most favorable weights of $v$ and $u$ such that the efficiency measure for the measured DMU is maximized.

$$
\begin{gathered}
\max \quad Y_{0}^{T} u+u_{*}, \\
\text { s.t. } \quad X_{0}^{T} v=1, \\
-X^{T} v+Y^{T} u+1 u_{*} \leq 0, \\
v, u \geq 0, \quad u_{*} \text { free. }
\end{gathered}
$$

\section{Data Availability}

The data used in this research are available upon request to the corresponding author.

\section{Conflicts of Interest}

The authors declare that they have no conflicts of interest.

\section{Acknowledgments}

This work was partially supported by the National Natural Science Foundation of China (Grant no. 71801013), the Beijing Social Science Foundation (Grant no. 18GLC078), and the Fundamental Research Funds for the Central Universities (Grant no. 2020JBW004).

\section{References}

[1] Y. Liu, W. Y. Szeto, and S. C. Ho, "A static free-floating bike repositioning problem with multiple heterogeneous vehicles, multiple depots, and multiple visits," Transportation Research Part C: Emerging Technologies, vol. 92, pp. 208-242, 2018.

[2] M. Kabak, M. Erbaş, C. Çetinkaya, and E. Özceylan, "A GISbased MCDM approach for the evaluation of bike-share stations," Journal of Cleaner Production, vol. 201, pp. 49-60, 2018.

[3] Y. Ma, J. Lan, T. Thornton, D. Mangalagiu, and D. Zhu, "Challenges of collaborative governance in the sharing economy: the case of free-floating bike sharing in Shanghai," Journal of Cleaner Production, vol. 197, pp. 356-365, 2018.

[4] A. Pal and Y. Zhang, "Free-floating bike sharing: solving reallife large-scale static rebalancing problems," Transportation Research Part C: Emerging Technologies, vol. 80, pp. 92-116, 2017.

[5] J. Liu, L. Qiao, Q. Meng et al., "Station site optimization in bike sharing systems," in Proceedings of the 2015 IEEE 
International Conference on Data Mining, Atlantic City, NJ, USA, November 2015.

[6] Z. Sun, Y. Li, and Y. Zuo, "Optimizing the location of virtual stations in free-floating bike-sharing systems with the user demand during morning and evening rush hours," Journal of Advanced Transportation, vol. 2019, Article ID 4308509, 11 pages, 2019.

[7] C.-C. Hsu, J. J. H. Liou, H.-W. Lo, and Y.-C. Wang, "Using a hybrid method for evaluating and improving the service quality of public bike-sharing systems," Journal of Cleaner Production, vol. 202, pp. 1131-1144, 2018.

[8] K. Frenken and J. Schor, "Putting the sharing economy into perspective," Environmental Innovation and Societal Transitions, vol. 23, pp. 3-10, 2017.

[9] I. Frade and A. Ribeiro, "Bike-sharing stations: a maximal covering location approach," Transportation Research Part A: Policy and Practice, vol. 82, pp. 216-227, 2015.

[10] J. C. Garcia-Palomares, J. Gutierrez, and M. Latorre, "Optimizing the location of stations in bike-sharing programs: a GIS approach," Applied Geography, vol. 35, no. 1-2, pp. 235-246, 2012.

[11] S. Mete, Z. A. Cil, and E. Özceylan, "Location and coverage analysis of bike-sharing stations in university campus," Business Systems Research Journal, vol. 9, no. 2, pp. 80-95, 2018.

[12] A. Giovannini, F. Malucelli, and M. Nonato, "Cycle-tourist network design," Transportation Research Procedia, vol. 22, pp. 154-163, 2017.

[13] L. M. Martinez, L. Caetano, T. Eiró, and F. Cruz, "An optimisation algorithm to establish the location of stations of a mixed fleet biking system: an application to the city of lisbon," Procedia-Social and Behavioral Sciences, vol. 54, pp. 513-524, 2012.

[14] J. G. Jin, H. Nieto, and L. Lu, "Robust bike-sharing stations allocation and path network design: a two-stage stochastic programming model," Transportation Letters, pp. 1-10. In press, 2019.

[15] M. Merakli and H. Yaman, "Robust intermodal hub location under polyhedral demand uncertainty," Transportation Research Part B: Methodological, vol. 86, pp. 66-85, 2016.

[16] P. Vogel, T. Greiser, and D. C. Mattfeld, "Understanding bikesharing systems using data mining: exploring activity patterns," Procedia-Social and Behavioral Sciences, vol. 20, pp. 514-523, 2011.

[17] T. Wuerzer, S. Mason, and R. Youngerman, "Boise bike share location analysis," Boise State University, Boise, ID, USA, 2012.

[18] N. Mohajeri and G. R. Amin, "Railway station site selection using analytical hierarchy process and data envelopment analysis," Computers \& Industrial Engineering, vol. 59, no. 1, pp. 107-114, 2010.

[19] M. H. M. Javadi, M. Ghandehari, and V. Hamidi Pouyandeh, "Locating of bicycle stations in the city of Isfahan using mathematical programming and multi-criteria decision making techniques," International Journal of Academic Research in Accounting, Finance and Management Sciences, vol. 3, no. 3, pp. 18-26, 2013.

[20] T. Kanjanakorn and M. Piantanakulchai, "Prioritizing suitable locations of bike sharing station by using the analytic hierarchy process (AHP)," in Proceedings of the International Symposium on the Analytic Hierarchy Process, Kuala Lumpur, Malaysia, June 2013.

[21] A. S. Loron and M. S. Loron, "An integrated fuzzy analytic hierarchy process-fuzzy data envelopment analysis (FAHP-
FDEA) method for intelligent building assessment," Tehnicki Vjesnik-Technical Gazette, vol. 22, no. 2, pp. 383-389, 2015.

[22] S. H. Mousavi-Nasab and A. Sotoudeh-Anvari, "A comprehensive MCDM-based approach using TOPSIS, COPRAS and DEA as an auxiliary tool for material selection problems," Materials \& Design, vol. 121, pp. 237-253, 2017.

[23] E. Ali Askari and M. Bashiri, "Design of a public bicyclesharing system with safety," Computational and Applied Mathematics, vol. 36, no. 2, pp. 1023-1041, 2017.

[24] N. Bozorgi and M. Abedzadeh, "A multiple criteria facility layout problem using data envelopment analysis," Management Science Letters, vol. 1, pp. 363-370, 2011.

[25] W. M. Bowen, "Subjective judgements and data envelopment analysis in site selection," Computers, Environment and Urban Systems, vol. 14, no. 2, pp. 133-144, 1990.

[26] T. L. Saaty, The Analytic Hierarchy Process: Planning, Priority Setting, Resource Allocation, McGraw-Hill, New York, NY, USA, 1980.

[27] T. Yang and C. Kuo, "A hierarchical AHP/DEA methodology for the facilities layout design problem," European Journal of Operational Research, vol. 147, no. 1, pp. 128-136, 2003.

[28] J. Shang and T. Sueyoshi, "A unified framework for the selection of a flexible manufacturing system," European Journal of Operational Research, vol. 85, no. 2, pp. 297-315, 1995.

[29] C. N. Wang, H. T. Tsai, T. P. Ho, V. T. Nguyen, and Y. F. Huang, "Multi-criteria decision making (MCDM) model for supplier evaluation and selection for oil production projects in Vietnam," Processes, vol. 8, no. 2, pp. 1-13, 2020.

[30] J. Korpela, A. Lehmusvaara, and J. Nisonen, "Warehouse operator selection by combining AHP and DEA methodologies," International Journal of Production Economics, vol. 108, no. 1-2, pp. 135-142, 2007.

[31] M. R. Khadivi and S. M. T. Fatemi Ghomi, "Solid waste facilities location using of analytical network process and data envelopment analysis approaches," Waste Management, vol. 32, no. 6, pp. 1258-1265, 2012.

[32] Y. Takamura and K. Tone, "A comparative site evaluation study for relocating Japanese government agencies out of Tokyo," Socio-Economic Planning Sciences, vol. 37, no. 2, pp. 85-102, 2003.

[33] R. Allen, A. Athanassopoulos, R. G. Dyson, and E. Thanassoulis, "Weights restrictions and value judgements in data envelopment analysis: evolution, development and future directions," Annals of Operations Research, vol. 73, pp. 13-34, 1997.

[34] M. P. L. Lins, A. C. Moreira da Silva, and C. A. K. Lovell, "Avoiding infeasibility in DEA models with weight restrictions," European Journal of Operational Research, vol. 181, no. 2, pp. 956-966, 2007.

[35] E. D. Mecit and I. Alp, "A new proposed model of restricted data envelopment analysis by correlation coefficients," Applied Mathematical Modelling, vol. 37, no. 5, pp. 3407-3425, 2013.

[36] V. V. Podinovski and A. D. Athanassopoulos, "Assessing the relative efficiency of decision making units using dea models with weight restrictions," The Journal of the Operational Research Society, vol. 49, no. 5, pp. 500-508, 1998.

[37] E. Murphy and J. Usher, "The role of bicycle-sharing in the city: analysis of the Irish experience," International Journal of Sustainable Transportation, vol. 9, no. 2, pp. 116-125, 2015.

[38] C. Cetinkaya, "Bike sharing station site selection for gaziantep," Sigma Journal of Engineer \& Nature Science, vol. 35, no. 3, pp. 535-543, 2017. 
[39] N. Subramanian and R. Ramanathan, "A review of applications of analytic hierarchy process in operations management," International Journal of Production Economics, vol. 138, no. 2, pp. 215-241, 2012.

[40] R. Stawicki and K. D. Lawrence, "Multiple criteria dea with and without weighting restrictions," Applications in Multicriteria Decision Making, Data Envelopment Analysis, and Finance, Emerald Publishing Limited, Bingley, UK, pp. 95104, 2010.

[41] T. Joro and P. J. Korhonen, Extension of Data Envelopment Analysis With Preference Information: Value Efficiency, Springer, Boston, MA, USA, 2015.

[42] W. Cook, A. Kazako, Y. Roll, and L. Seiford, "A data envelopment approach to measuring efficiency: case analysis of highway maintenance patrols," The Journal of Socio-Economics, vol. 20, no. 1, pp. 83-103, 1991.

[43] P. Zhou, B. Ang, and K. Poh, "Measuring environmental performance under different environmental DEA technologies," Energy Economics, vol. 30, no. 1, pp. 1-14, 2008.

[44] C. Kao and H. Hung, "Efficiency analysis of university departments: an empirical studyst," Omega, vol. 36, no. 4, pp. 653-664, 2008.

[45] J. Soleimani-Damaneh, M. Hamidi, and H. Sajadi, "Evaluating the performance of Iranian football teams utilizing linear programming," American Journal of Operations Research, vol. 1, no. 2, pp. 65-72, 2011.

[46] J. E. Beasley, "Comparing university departments," Omega, vol. 18, no. 2, pp. 171-183, 1990.

[47] Y. Roll, W. D. Cook, and B. Golany, "Controlling factor weights in data envelopment analysis," IIE Transactions, vol. 23, no. 1, pp. 2-9, 1991.

[48] V. V. Podinovski, "Side effects of absolute weight bounds in DEA models," European Journal of Operational Research, vol. 115, no. 3, pp. 583-595, 1999.

[49] Y.-H. B. Wong and J. E. Beasley, "Restricting weight flexibility in data envelopment analysis," The Journal of the Operational Research Society, vol. 41, no. 9, pp. 829-835, 1990.

[50] R. G. Thompson, L. N. Langemeier, C. T. Lee, E. Lee, and R. M. Thrall, "The role of multiplier bounds in efficiency analysis with application to Kansas farming," Journal of Econometrics, vol. 46, no. 1-2, pp. 93-108, 1990.

[51] G. E. Halkos, N. G. Tzeremes, and S. A. Kourtzidis, "Weight assurance region in two-stage additive efficiency decomposition DEA model: an application to school data," Journal of the Operational Research Society, vol. 66, no. 4, pp. 696-704, 2015.

[52] R. G. Thompson, F. D. Singleton, R. M. Thrall, and B. A. Smith, "Comparative site evaluations for locating a highenergy physics lab in Texas," Interfaces, vol. 16, no. 6, pp. 35-49, 1986.

[53] D. Chang and J. Y. Wang, "A new model to improve the subjectivity of AHP," Value Engineering, vol. 9, pp. 32-34, 2004.

[54] A. Charnes, W. W. Cooper, and E. Rhodes, "Measuring the efficiency of decision making units," European Journal of Operational Research, vol. 2, no. 6, pp. 429-444, 1978.

[55] R. D. Banker, A. Charnes, and W. W. Cooper, "Some models for estimating technical and scale inefficiencies in data envelopment analysis," Management Science, vol. 30, no. 9, pp. 1078-1092, 1984. 